\title{
Exploring the potential of xanthene derivatives for antitubercular activity
}

\author{
Chitre TS ${ }^{* 1}$, Khedkar VM' ${ }^{2}$, Asgaonkar KD ${ }^{1}$, Dube AS ${ }^{1}$, Shurpali K ${ }^{3}$, Sarkar D ${ }^{3}$, Kathiravan $\mathrm{M}^{4}$ and Jha PC \\ ${ }^{1}$ All India Shri Shivaji Memorial Society's college of Pharmacy, Kennedy Road, Pune, India \\ ${ }^{2}$ Smt. Kashibai Navale College of Pharmacy (SKNCOP), Kondhwa Saswad Road, Kondhwa (Bk.), Pune, India \\ ${ }^{3}$ Combi-Chem Bioresource Centre, CSIR-National Chemical Laboratory, Dr. Homi Bhabha Road, Pune, India \\ ${ }^{4}$ Department of Pharmaceutical Chemistry, SRM College of Pharmacy SRM University Kattankulathur, Kancheepuram, India \\ ${ }^{5}$ School of Chemical Sciences, Central University of Gujarat, Sector-30, Gandhinagar, Gujarat, India
}

\begin{abstract}

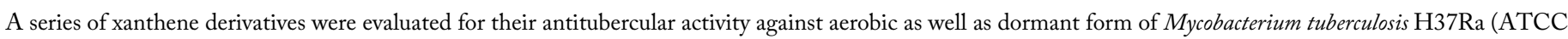
25177). Antitubercular screening was performed using (XTT) and menadione assay. Compound 1 inhibited aerobic M. tuberculosis H37Ra (ATCC 25177) with MIC of $0.30 \mu \mathrm{g} / \mathrm{ml}\left(\mathrm{IC}_{50}=0.118 \mu \mathrm{g} / \mathrm{ml}\right)$ and interestingly it showed higher percentage inhibition in anaerobic assay compared to Rifampin. It was also explored for its immunomodulatory potential using in vitro and in vivo techniques. An insight to lead optimization was obtained through docking studies of the synthesized compounds performed using the crystal structure of TMPKmt.
\end{abstract}

\section{Introduction}

Tuberculosis (TB) caused by Mycobacterium tuberculosis (MTB) is a global public health problem [1]. The control of the disease is often compromised due to serious side effects of currently available antitubercular drugs and emergence of resistant strains of MTB [2]. Higher potency, efficiency against active as well as dormant forms are some of the criterions for development of new drugs for tuberculosis [3]. The enzyme, Mycobacterial thymidine monophosphate kinase (TMPKmt) is a key enzyme that synthesizes nucleotides using, adenosine triphosphate (ATP) as a phosphoryl donor. Thus, inhibitors of TMPKmt are explored as potential anti-TB agents targeting deoxy nucleic acid (DNA) replication [4].

Various pharmacological activities have been reported for the heterocyclic scaffold of tricyclic dibenzopyrans, viz., xanthenes [5]. In an attempt to further explore the tricyclic dibenzopyrans scaffold, we have previously reported efficient synthesis of few xanthenes derivatives as shown in Figure 1 and Table 1 [6].

Promising antimycobacterial as well as immunomodulatory

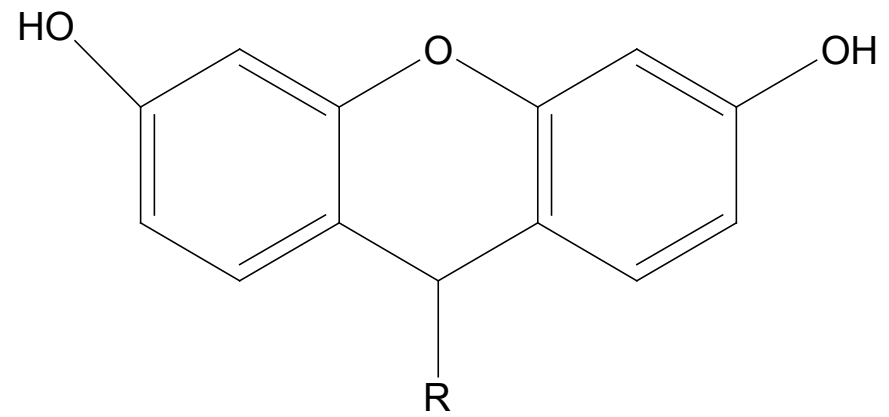

Figure 1. General structure for previously synthesized xanthenes derivatives. activities are reported for xanthenone derivatives [7,8]. Thus, in continuation of our efforts in antitubercular research $[9,10]$ and having considered the structural similarity of these two tricyclic dibenzopyrans viz., xanthene derivatives synthesized by us and the reported antimycobacterial and immunomodulatory xanthone derivatives, the synthesized derivatives have been investigated herein, for the antimycobacterial and immunomodulatory activities. Furthermore, to gain insight into the probable mechanism of action or binding mode of these xanthene derivatives, the title compounds have been docked into the active site of TMPKmt.

\section{Results and discussion}

\section{Biological activities}

The in vitro antitubercular screening against MTB $H 37 R a$, was performed using 2, 3-bis [2-methyloxy-4-nitro-5-sulfophenyl]-2H-

Table 1. Xanthene derivatives.

\begin{tabular}{|c|c|}
\hline Compound No. & $\mathbf{R}$ \\
\hline 1 & 4-Chlorophenyl \\
\hline 2 & 2-Nitrophenyl \\
\hline 3 & 4-Nitrophenyl \\
\hline 4 & 4-Hydroxyphenyl \\
\hline 5 & 4-Methoxyphenyl \\
\hline 6 & -styryl \\
\hline
\end{tabular}

Correspondence to: Dr. Trupti S. Chitre, Associate Professor, All India Shri Shivaji Memorial Society's College of Pharmacy, Kennedy Road, Pune, India, E-mail: chitretrupti@rediffmail.com

Key words: Xanthenes, antitubercular, dormant, immunomodulatory activity, docking

Received: March 02, 2017; Accepted: April 06, 2017; Published: April 10, 2017 
tetrazolium-5-carboxanilide (XTT) and menadione (XRMA) assay using microplate reader [11]. The in vitro immunomodulatory activity evaluation was performed for the most active antitubercular xanthene viz. 1 using phagocytic and respiratory burst (RB) assay techniques [12-15]. The lethal dose $\left(\mathrm{LD}_{50}\right)$ value of compound $\mathbf{1}$ was determined in albino mice as per organization of economic and co-operation development (OECD) guidelines [16]. The compound 1 was further evaluated using in vivo immunomoudulatory assay post its acute toxicity study as per the reported procedures [17-19]. Further the compounds have been docked into the active site of TMPKmt $[20,21]$.

\section{In vitro antitubercular evaluation}

For the XRMA assay against MTB $H 37 R a$, solutions of the xanthenes derivatives [1-6;10 mg/ml in dimethyl sulphoxide (DMSO)] were aseptically transferred to the individual wells of sterile 96-well plates at a final concentration of $100 \mu \mathrm{g} / \mathrm{ml}$ for preliminary screening and a dose response curve of compounds was carried out by making serial dilutions in DMSO. $250 \mu \mathrm{l}$ of MTB H37Ra culture containing approximately $10^{5}$ cells $/ \mathrm{ml}$ was aseptically transferred to each well and the plate was sealed. All the compounds were screened against active and dormant strains of MTB H37Ra.The MIC and $\mathrm{IC}_{50}$ of all the compounds against active MTB $H 37 R a$ and percent inhibition obtained against anaerobic MTB $H 37 R a$, at $30 \mu \mathrm{g} / \mathrm{ml}$ is given in Table 2 . The substitution of 4-chlorophenyl at 9 position in xanthene derivatives resulted in most active compound with $\mathrm{MIC}$ and $\mathrm{IC}_{50}$ of $0.31 \mu \mathrm{g} / \mathrm{ml}$ and $0.116 \mu \mathrm{g}$ respectively. The compound $\mathbf{1}$ has also shown the highest $\%$ inhibition (67\%) of dormant MTB H37Ra strain. Rifampin was used as a standard.

\section{In vitro Immunomodulatory activity evaluation}

The in vitro immunomodulatory activity evaluation was performed for the most active antitubercular xanthene viz., compound 1, using phagocytic and respiratory burst (RB) assay techniques [1215]. In phagocytic assay, $0.1 \mathrm{ml}$ solution of different concentrations of compound 1, prepared in DMSO were placed in test tubes and leucocytes suspension $\left(5 \times 10^{6} / \mathrm{ml}\right)$ was aseptically transferred to each of the test tube. It was covered with MTB H37 Rv strain $\left(6 \times 10^{8}\right.$ bacteria/ $\mathrm{ml}$ ) and incubated further for 2 hours at room temperature. The smear was prepared on glass slide, allowed to dry at room temperature and fixed by methanol. It was then stained with Ziel-Nelson stain and observed under the microscope. The same procedure was followed for the control except in place of test solutions, the volume was made with MEM solution. A minimum of $100 \mathrm{WBC}$ 's were counted and the number of mycobacteria engulfed by each of them was recorded. The result is expressed as mean of these engulfed mycobacteria viz., mean particle number (MPN). The mean numbers of mycobacterial cellsphagocytosyzed, by WBC were found to be comparable to the control (Table 3).

In the RB assay, phosphate buffer saline solution (PBS) served as a negative control and endotoxin-activated plasma solution represented the positive control for the test. The solutions of different concentrations of compound $\mathbf{1}$ prepared in DMSO were taken, the leucocytes suspension $\left(5 \times 10^{6} / \mathrm{ml}\right)$ was aseptically transferred to each of the test tube followed by addition of Nitroblue tetrazolium (NBT) solution $(0.1 \mathrm{ml}, 0.1 \%$ solution $)$ and incubated at $37^{\circ} \mathrm{C}$ for 20 min. Smears were then prepared on glass slide and $4 \mathrm{ml}$ of counting fluid was added. It was dried, fixed by heating and counterstained with Jenner-Giemsa and observed under oil immersion. Around 100 neutrophils were counted for percentage of NBT positive cells, which were identified as cells containing blue granules/lumps. The compound 1 showed about $49 \%$ stimulation of phagocytic activity at a concentration of $6.25 \mu \mathrm{g} / \mathrm{ml}$, compared to the positive control (42\%) (Table 3 ) at a similar concentration.

\section{Determination of lethal dose $\left(\mathrm{LD}_{50}\right)$}

The lethal dose $\left(\mathrm{LD}_{50}\right)$ value of compound 1 was determined in albino mice as per Organization of Economic and Co-operation Development guidelines [16]. Oral administration of compound 1 did not produce any toxic effects in mice. The data was analyzed with the help of AOT425 Software. As there were no signs of mortality or any

Table 2. Antitubercular activity against $M$. tuberculosis $H 37 R a$ (aerobic and anaerobic).

\begin{tabular}{|c|c|c|c|}
\hline \multirow[t]{2}{*}{ Compound No. } & \multirow{2}{*}{$\begin{array}{c}\text { The \% inhibition against MTB } H 37 R a \\
\text { (anaerobic) at } 30 \mu \mathrm{g} / \mathrm{ml}\end{array}$} & \multicolumn{2}{|c|}{ MTB H37Ra (aerobic) } \\
\hline & & $\operatorname{MIC}(\mu \mathrm{g} / \mathrm{ml})$ & $\mathrm{IC}_{50}(\mu \mathrm{g} / \mathrm{ml})$ \\
\hline 1 & 66.86 & 0.31 & 0.116 \\
\hline 2 & 48.00 & 2.7 & 0.57 \\
\hline 3 & 45.47 & 2.1 & 0.67 \\
\hline 4 & 32.42 & 30.45 & 2.35 \\
\hline 5 & 32.42 & 2.66 & 0.71 \\
\hline 6 & 35.75 & 6.78 & 2.8 \\
\hline Rifampin & 50.00 & 0.012 & 0.020 \\
\hline
\end{tabular}

Table 3. Percentage of Reduced Lymphocytes Particle number of killed MTB H37 Rv after treatment with compound1 in Phagocytic and RB assay.

\begin{tabular}{|c|c|c|c|c|c|}
\hline \multirow[t]{2}{*}{ Sample } & \multicolumn{5}{|c|}{ Concentrations $(\mu \mathrm{g} / \mathrm{ml})$ of 1} \\
\hline & 100 & 50 & 25 & 12.5 & 6.25 \\
\hline $\begin{array}{l}\text { Phosphate Buffer Saline Solution } \\
\text { (Normal control) }\end{array}$ & $29.04 \pm 0.39$ & $28.10 \pm 0.35$ & $28.00 \pm 0.04$ & $26.45 \pm 0.05$ & $25.20 \pm 0.08$ \\
\hline $\begin{array}{l}\text { E. coli endotoxin activated plasma } \\
\text { (Positive Control) }\end{array}$ & $45.12 \pm 0.86$ & $45.05 \pm 0.17$ & $44.30 \pm 0.04$ & $43.02 \pm 0.2$ & $42.21 \pm 0.22$ \\
\hline Compound $1(a)$ & $67.01 \pm 0.14 * * *$ & $61.00 \pm 0.62 * * *$ & $58.05 \pm 0.04 * * *$ & $53.23 \pm 0.09 * *$ & $49.34 \pm 0.04 * *$ \\
\hline Suspension A (control) & $5-6$ & 5 & 4 & 3 & 2 \\
\hline Compound $1(b)$ & 5 & 5 & $4-5$ & 4 & 3 \\
\hline
\end{tabular}

$a$. The data is expressed as mean percentage reduced neutrophils \pm standard error of mean. Significant difference from positive control (Std.) by one way ANOVA followed by Dunnet's test $(\mathrm{n}=3) * * * p<0.0001$ and $) * * p<0.001$

$b$. The data is expressed as mean particle number phagocytosyzed. 
clinical abnormality, the test compound was found to be safe up to $2000 \mathrm{mg} / \mathrm{kg}$ (Table 4).

\section{In vivo immunomoudulatory activity evaluation}

The compound $\mathbf{1}$ was further evaluated using in vivo immunomoudulatory assay post its acute toxicity study as per the reported procedure [17-19]. 24 mice (20-30 gm) were divided into 4 groups of 6 animals each. Group I (control group) and group II (Cyclophosphamide treated control) received the vehicle for a period of 13 days. Groups III-IV were given compound $1(10 \mathrm{mg} / \mathrm{kg}$ and 20 $\mathrm{mg} / \mathrm{kg}$, p.o. respectively) daily for 13 days. The animals of groups IIIV were injected with cyclophosphamide $\left(30 \mathrm{mg} / \mathrm{kg}\right.$, i.p.) on the $11^{\text {th }}$, $12^{\text {th }}$ and $13^{\text {th }}$ day, 1 hour after the administration of the respective treatment. Blood samples were collected on the day before (day 0 ) and on the $14^{\text {th }}$ day of the experiment and the total white blood cell (WBC) count was determined. Cyclophosphamide treatment for the period of 03 days showed significant reduction $(\mathrm{p}<0.001)$ in WBC count and thereby exerted immunosuppressant effect. This effect was significantly prevented by pretreatment with compound $\mathbf{1}$ at two different doses, 10 $\mathrm{mg} / \mathrm{kg}$ and $20 \mathrm{mg} / \mathrm{kg}$. The results are depicted in Figure 2.

\section{Docking studies}

Further the synthesized compounds have been docked into the active site of TMPKmt $[20,21]$. To ensure that the ligand orientation obtained from the docking experiment were likely to represent valid and reasonable binding modes of the inhibitors, the docking parameters had to be first validated for the crystal structure. The most appropriate method for evaluating the accuracy of a docking protocol is to determine how closely the lowest energy pose predicted by docking resembles the experimentally determined binding mode by

Table 4. Acute toxicity assessment.

\begin{tabular}{|c|c|c|}
\hline Test Seq. & Dose(mg/kg) & Result \\
\hline 1 & 175 & $\mathrm{O}$ \\
\hline 2 & 550 & $\mathrm{O}$ \\
\hline 3 & 2000 & $\mathrm{O}$ \\
\hline
\end{tabular}

$*(X=$ Died, $O=$ Survived $) ;$ Dose recommendation: The main test is complete; stopping criterion met: 3 at limit dose).

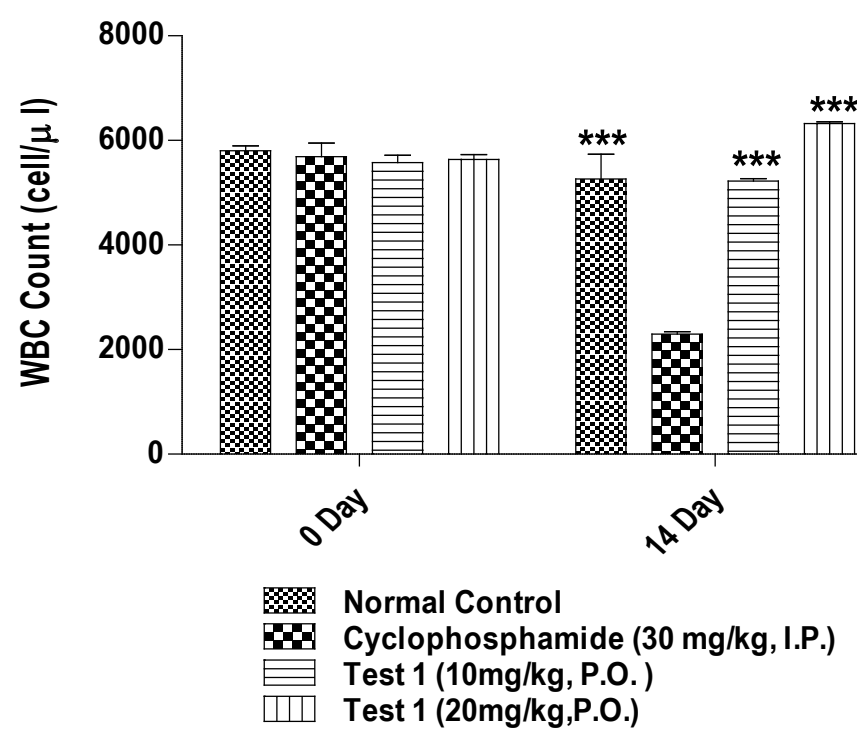

Figure 2. Evaluation of in vivo immunomodulatory activity. (\# Data is shown as Mean \pm S.E.M. $(\mathrm{n}=6)$; One way ANOVA Followed by Dunnett's Test, *** Significantly different as compared to Cyclophosphamide alone group.* $\mathrm{p}<0.001$ ).
X-ray crystallography. In the present study, the docking protocol was validated by extracting the native ligand from the crystal structure of Thymidylate kinase and re-docking back into its active site. Results of control docking showed a very low RMS deviation of $0.22 \AA$ A between the docked conformation and the original orientation found in the X-ray crystal structure. Thus, the reliability of the Glide docking protocol for predicting binding modes of Xanthene derivatives in the dataset was confirmed. The best scoring pose for the native ligandDeoxythymidine obtained by docking has been compared against the crystal structure in Figure 3.

\section{Results}

Results of the docking study have been analyzed based on three main parameters - Glide score, Glide energy and non-bonded interactions (van der Waals and Coulombic) (Table 5). Considering these parameters the binding affinity of the xanthene derivatives towards thymidylate kinase enzyme has been discussed. From the ensuing docked structures, it is clear that all the six xanthene derivatives (1-6) snugly fit into the active site of the enzyme, in positions very close to that of the native ligand- Deoxythymidine in the crystal structure. Their docking scores varied from -6.15 to -11.85 with a average score of -8.38 while the docking score for the native ligand was found to be -8.31. A correlation plots for the $\%$ inhibition observed against MTB H37RA by XRMA (aerobic) at $1 \mu \mathrm{g} / \mathrm{ml}$ versus the Glide docking score of the xanthenes derivatives is shown in Figure 4. A very significant correlation was observed between the experimentally observed antitubercular activity and the theoretical predictions from molecular docking with the active compounds having scored high while those with relatively low inhibition are also predicted to have lower docking score. A detailed per-residue interaction analysis between the thymidylate

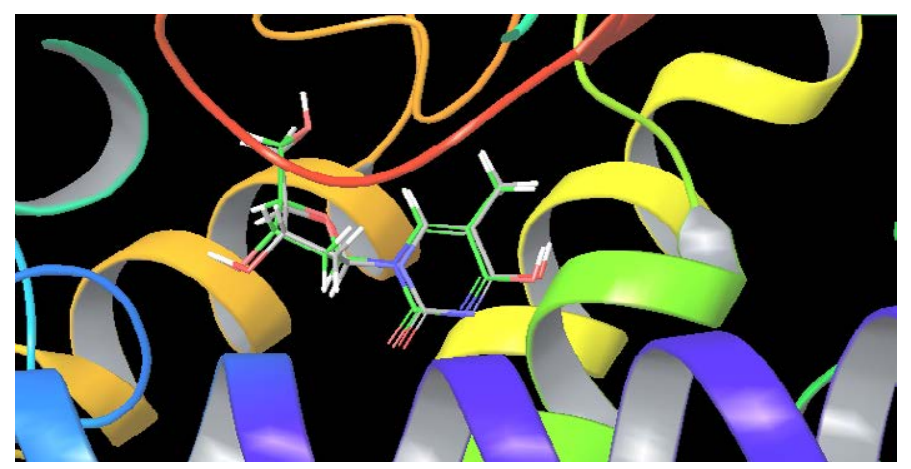

Figure 3. Overlay of the X-ray conformation of native ligand- Deoxythymidine over its best docked conformation.

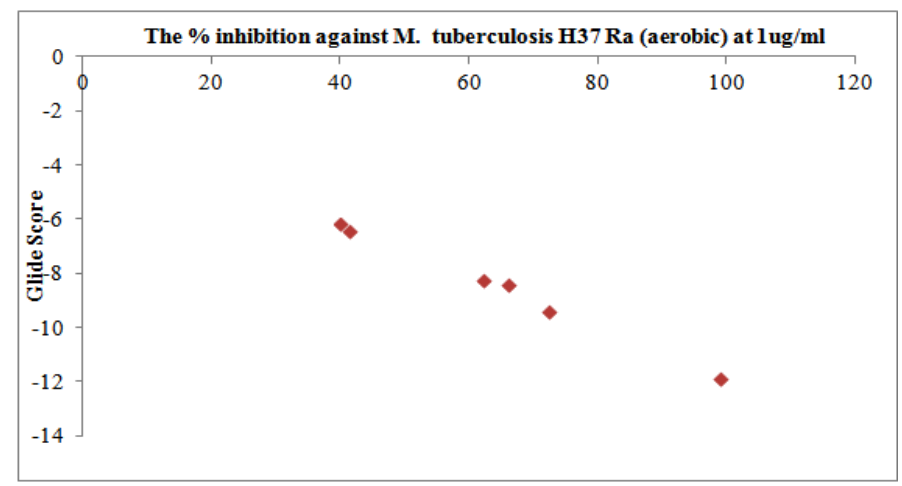

Figure 4. The correlation plots of the \% inhibition observed against MTB H37Ra by $\mathrm{XRMA}($ aerobic) at $1 \mu \mathrm{g} / \mathrm{ml}$ versus the Glide docking score of the xanthenes derivatives. 
Table 5. Quantitative analysis of the molecular docking study-Glide score, Glide energy and non-bonded interactions (van der Waals ;(vdw) and electrostatic) along with the experimental antitubercular data.

\begin{tabular}{|c|c|c|c|c|c|c|}
\hline $\begin{array}{l}\text { Compound } \\
\text { Number }\end{array}$ & $\begin{array}{c}\text { MIC } \\
(\mu g / m l) \text { against } \\
\text { MTB H37Ra by XRMA (aerobic) }\end{array}$ & $\begin{array}{l}\text { The \% inhibition against } \\
\text { MTB } H 37 R a \text { by XRMA } \\
\text { (aerobic) at } 1 \mu \mathrm{g} / \mathrm{ml}\end{array}$ & Glide score & Glide Energy & vdW energy & Coulombic energy \\
\hline 1 & 0.31 & 99.01 & -11.85 & -75.81 & -44.87 & -30.93 \\
\hline 2 & 2.70 & 72.17 & -9.36 & -70.29 & -44.85 & -25.44 \\
\hline 3 & 2.10 & 66.04 & -8.36 & -65.32 & -44.14 & -21.18 \\
\hline 4 & 30.45 & 41.37 & -6.39 & -46.41 & -30.34 & -16.07 \\
\hline 5 & 2.66 & 62.19 & -8.19 & -59.45 & -42.16 & -17.29 \\
\hline 6 & 6.78 & 39.94 & -6.15 & -44.04 & -29.55 & -14.48 \\
\hline
\end{tabular}
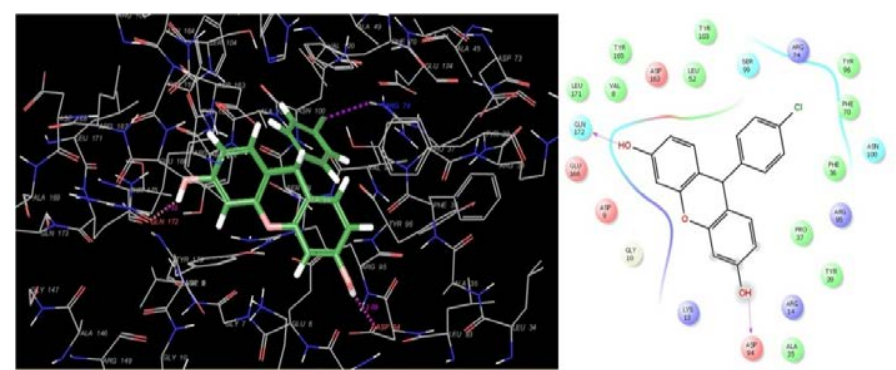

Figure 5. Binding mode of the most active compound 1 into the active site of thymidylate kinase.

kinase enzyme and the six xanthene derivatives was carried out which could provide an explanation for the factors governing the variation observed in the experimental antitubercular activity. However, for the sake of brevity we have compared the per-residue interactions analysis in detailed only for the most active compound $\mathbf{1}$ and the least active compound 6 .

Analysis of the docking poses of compound 1 (Figure 5) and compound 6 (Figure 6) shows that both the ligands occupy the binding site of thymidylate kinase in the coordinates very close to that of native ligand in the crystal structure. Though the $p$-chlorophenyl and styryl side chain of compound $\mathbf{1}$ and $\mathbf{6}$ respectively protrude in the same direction in the active site, their backbone nuclease did not overlap which could be one reason for the variation observed in their binding affinities and the associated thermodynamic interactions (Figure 7). Inspection of the non-bonded interaction energies shows that for both compounds $\mathbf{1}$ and $\mathbf{6}$, the van der Waals interaction energy component dominated over the coulombic component in the overall binding energy. The overall binding energy of compound 1 was also found to be significantly higher $(-75.81 \mathrm{kcal} / \mathrm{mol})$ than compound 6 $(-44.04 \mathrm{kcal} / \mathrm{mol})$. These numbers rationalizes the tighter binding of compound $\mathbf{1}$ into the active site of thymidylate kinase than that of lesser active compound $\mathbf{6}$. This difference in binding affinity can be further explained in terms of the specific bonded and non-bonded per residue interactions observed with the residues in the active site. Analysis of the docking pose of compound $\mathbf{6}$ showed that it formed an extensive chain of favorable van der Waals interactions with Asp163 $(-2.04 \mathrm{kcal} / \mathrm{mol})$, Asn100 $(-1.60 \mathrm{kcal} / \mathrm{mol})$, Ser99 $(-1.97 \mathrm{kcal} / \mathrm{mol})$, Asp94 (-1.03 kcal/mol), Phe70 (-3.87 kcal/mol), Tyr39 $(-1.19 \mathrm{kcal} / \mathrm{mol})$ and Phe36 $(-1.88 \mathrm{kcal} / \mathrm{mol})$ residues in the active site. Compound 6 is also stabilized within the active site through favorable van der Waals contacts with Asp163 (-1.90 kcal/mol), Asn100 (-1.02 kcal $/ \mathrm{mol})$, Ser99 $(-1.21 \mathrm{kcal} / \mathrm{mol})$, Phe70 (-1.60 kcal/mol), Tyr39 $(-1.03 \mathrm{kcal} / \mathrm{mol})$ and Phe36 $(-1.00 \mathrm{kcal} / \mathrm{mol})$. However, no van der Waals interaction was observed with Asp94 as seen in compound 1. Also, the strength of per-residue interaction was found to be weaker for compound 6 compared to compound 1. A similar observation was noticed in
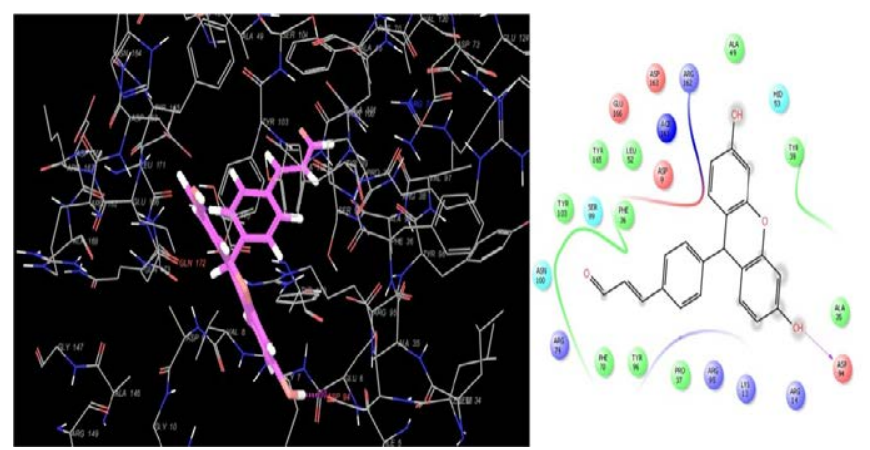

Figure 6. Binding mode of the least active compound 6 into the active site of thymidylate kinase.

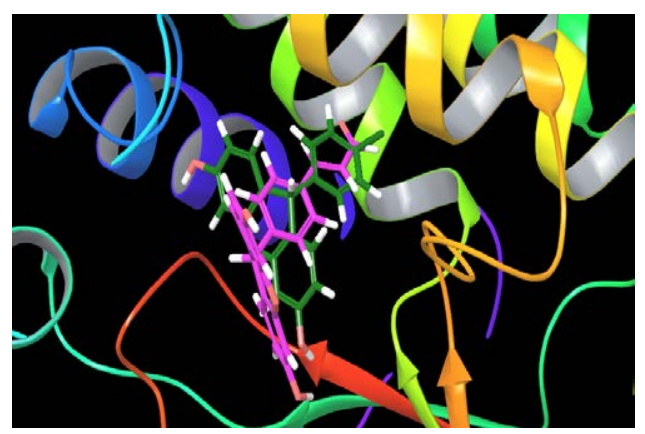

Figure 7. Overlay of the docking pose of the most active compound 1 versus the least active compound 6 .

terms of electrostatic interactions. Compound 1 was found to be involved in a series of favorable coulombic interactions with $\mathrm{Gln} 172$ $(-3.29 \mathrm{kcal} / \mathrm{mol}), \operatorname{Arg} 95(-2.49 \mathrm{kcal} / \mathrm{mol})$, Asp94 $(-3.51 \mathrm{kcal} / \mathrm{mol})$ and Arg74 $(-1.20 \mathrm{kcal} / \mathrm{mol})$ while compound 6 showed weaker interactions with these residues: $\operatorname{Gln}(172(-1.29 \mathrm{kcal} / \mathrm{mol}), \operatorname{Arg} 95(-1.02 \mathrm{kcal} / \mathrm{mol})$, Asp94 $(-1.75 \mathrm{kcal} / \mathrm{mol})$ and $\mathrm{Arg} 74(-1.05 \mathrm{kcal} / \mathrm{mol})$. The enzymeinhibitor complex of both compounds, $\mathbf{1}$ and $\mathbf{6}$ was found to be further stabilized by a hydrogen bonding interactions observed with Asp94. Compound 1 also showed an additional hydrogen bonding interaction with Gln172 which was not observed for compound 6 . The hydrogen bonding interaction serve as an "anchor", determining the 3D position of a molecule in the active site, thereby facilitating the steric and electrostatic interactions.

\section{Conclusion}

Amongst all the derivatives, 1, 9-(4-Chlorophenyl)-9H-xanthene3,6-diol has shown highest percentage inhibition viz., 95.24 of replicating MTB H37Ra, at a concentration of $0.39 \mu \mathrm{g} / \mathrm{ml}$. The standard used was Rifampicin, which showed MIC of $0.012 \mu \mathrm{g} / \mathrm{ml}$. The compound 1 has also shown better inhibition (67\%) of dormant MTB $H 37 R a$, compared to Rifampicin (50\%) at a concentration of $30 \mu \mathrm{g} / \mathrm{ml}$. 
For efficient phagocytosis and intracellular killing of MTB, production of reactive oxygen species (ROI's) is required. NBT dye reduction test gives information about phagocytic activity and intracellular killing function of neutrophils. In phagocytic assay as well as in NBT dye test (RB assay) our compound $\mathbf{1}$ has significantly increased the phagocytic function of human neutrophils. It has shown $49 \%$ upregulation of NBT dye reduction, by the neutrophils at a concentration of $6.25 \mu \mathrm{g} /$ $\mathrm{ml}$, compared to the positive control viz., E. coli endotoxin activated plasma, which showed $42 \%$ activity at similar concentration. The mean particle number of killed MTB H37R $v$ after treatment with compound 1 was found comparable $(\mathrm{MPN}=3)$ with the control $(\mathrm{MPN}=2)$ at a concentration of $6.25 \mu \mathrm{g} / \mathrm{ml}$. The acute toxicity studies of compound 1 showed that it is safe up to $2000 \mathrm{mg} / \mathrm{kg}$. The compound $\mathbf{1}$ was further explored for its immunostimulant activity using in vivo model, viz., cyclophophamide induced myelosupression in mice. The results showed that there is a marked decrease in the WBC count, in control versus the induction group. The compound $\mathbf{1}$ at a concentration of $10 \mathrm{mg} / \mathrm{kg}$ and $20 \mathrm{mg} / \mathrm{kg}$ have significantly $\left({ }^{*} \mathrm{p}<0.001\right)$ increased the WBCs count, and restored the myelosuppressive effects induced by cyclophosphamide.

We have thus shown here that the xanthene derivative $\mathbf{1}$ increases the phagocytic activity of macrophages in a dose-dependent manner. The xanthene derivative $\mathbf{1}$ has shown antitubercular activity not only against the replicating MTB but also against the dormant form of the disease. Most importantly, the results of molecular docking study revealed the possible binding interactions with the enzyme TMPKmt, which could help in future lead optimization for this target.

\section{Acknowledgements}

The authors are thankful to Dr. Ashwini R. Madgulkar, Principal AISSMS College of Pharmacy, for continuous motivation, support and providing necessary infrastructure to carry out this work. Thanks are also due to, Dr. K.G.Bhat, Head of the department (Microbiology) M.M. Dental College and Research, Belgaum, India for providing us the facilities for performing the in vitro immunomodulatory assays. We would like to thank Central University of Gujarat for providing basic computational facilities. We also thank Schrödinger for providing the Demo license of Schrödinger Suite and especially Vinod Devarji for delivering valuable technical support that has tremendously helped in this study.

\section{References}

1. Global Tuberculosis report Published by World Health Organization; 2015, WHO Press: Geneva, Switzerland.

2. Udwadia ZF, Amale RA, Ajbani KK, Rodrigues C (2011) Clin Infect Dis Corres 3: 1-2.

3. Owono L, Keita M, Megnassan E, Frecer V, Miertus S (2013) Tuberculosis Research and Treatment.

4. Calenbergh SV, Pochet S, Munier-lehmann H (2012) Current Topics in Medicinal Chemistry 12: 694-705

5. Sashidhara KV, Kumar A, Dodda RP, Kumar B (2012) Tetrahedron Lett 53: 3281- 3283

6. Kathiravan MK, Vidyasagar N, Nanda R, Mangal R (2012) Synth Commu 21: 1-23.

7. Szkaradek N, Stachura K, Waszkielewicz AM, Cegla M, Szneler E, et al. (2008) Acta Poloniae Pharmaceutica - Drug Res 65: 21-28.

8. Pang JH, Cao Z, Joseph BC, Ching LM (1998) Euro. J. of Cancer 34: 1282-1289.

9. Raparti V, Chitre TS, Bothara KG, Kumar V, Dangre S, et al. (2009) Euro Jou of Medicinal Chem 44: 3954-3960.

10. Chitre TS, Bothara KG, Bhandari SV, Jalnapurkar R, Kathiravan MK (2011) Chem Biol Drug Des 78: 826-834.

11. Singh U, Akhtar S, Mishra A, Sarkar D (2011) Jou of Microbiol Methods 84: 202-207.

12. Gooi HC, Chapel H (1990) In Clinical Immunology: A Practical Approach; England Oxford, 51-78.

13. Fiorenza G, Farroni M, Bogue C, Selenscig D, Lamas D, et al. (2007) Archives of Medi Res 38: 526-533.

14. Ghule B, Yeole P (2012) Jou of Ethnopharmacology 141: 424-431.

15. Manosroi A, Saraphanchotiwitthaya A, Manosroi J (2006) Fitoterapia 77: 189-193.

16. Organization for Economic Co-operation and Development guidelines OECD (2000), $425,2000$.

17. Ziauddin N, Phansalkar N, Patki P, Diwanay S, Patwardhan B (1996) Jou of Ethnopharmaco 50: 69-76.

18. Jayathirtha MG, Mishra SH (2004) Phytomedicine 11: 361-365.

19. Shukla S, Mehta A, John J, Mehta P, Shukla S (2009) Jou of Ethnopharmacology 125: 252-256.

20. Friesner RA, Banks JL, Murphy RB, Halgren TA, Klicic JJ, et al. (2004) Jou of Medicinal Chemistry 47: 1739-1749.

21. Halgren TA, Murphy RB, Friesner RA, Beard HS, Frye LL, et al. (2004) Jou of Medicinal Chemiistry 47: 1750-1759.

Copyright: (C2017 Chitre TS. This is an open-access article distributed under the terms of the Creative Commons Attribution License, which permits unrestricted use, distribution, and reproduction in any medium, provided the original author and source are credited. 